\title{
The SGIM Policy Analysis: Supporting the Generalist Voice for Participation in Policymaking
}

\author{
Lisa V. Rubenstein, MD, MSPH ${ }^{1,2,3}$ and Nancy A. Rigotti, MD

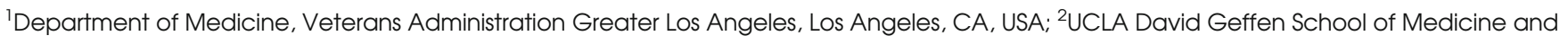 \\ School of Public Health, Los Angeles, CA, USA; ${ }^{3}$ RAND, Santa Monica, CA, USA; ${ }^{4}$ Division of General Medicine, Massachusetts General Hospital \\ and Harvard Medical School, Boston, MA, USA.
}

J Gen Intern Med 24(7):888-9

DOI: $10.1007 / \mathrm{s} 11606-009-1025-6$

(C) Society of General Internal Medicine 2009

$\mathrm{T}$ his issue of JGIM contains an article entitled "High Quality Care and Ethical Pay-for-Performance: A Society of General Internal Medicine Policy Analysis" by Wharam and colleagues ${ }^{1}$. The importance of this topic is addressed in an accompanying thought-provoking editorial by Dr. Matt Wynia. This second editorial has a different purpose. We highlight the Wharam article as SGIM's first full example of an officially sanctioned SGIM policy analysis.

While SGIM has always developed position papers on key issues of relevance to our members, the Society has not previously used a systematic process to publish in-depth analyses of its positions in JGIM. Because the product is new for SGIM, this editorial outlines how it developed from an idea to a finished product, focusing on how the preparation and review of the document differs from the typical journal article. By doing so, we hope to inspire SGIM members, committees, interest groups, and task forces to create other policy analyses addressing the critical issues facing general internal medicine practice, education, and research.

SGIM's Council and Health Policy Committee have long wrestled with the challenge of how best to articulate the views of SGIM members on problems and issues facing general internal medicine. This is a critical role for our Society, and one that has become more pressing recently as the prospects for major health-care reform escalate. The central role of primary care appears to be poised for recognition at the same time that the declining workforce threatens the future of our field.

At this critical juncture, how can SGIM make its voice heard? We believe that as an organization, SGIM is well positioned to exert influence. SGIM represents a broad-based generalist point of view. We have strong connections to academic medicine and to the trainees who represent the future of our field. Among medical societies, SGIM has gained credibility by establishing its independence from for-profit pharmaceutical and other industries involved in health-care delivery. These are among the qualities that lead other societies and political entities to request SGIM's participation or support. Yet our member-supported financing, our support for research, education, and quality improvement activities,

Published online June 5, 2009 and our reliance primarily on volunteer labor limit the number of policy issues in which our governing bodies can effectively engage.

A solution to this dilemma is to engage SGIM committees and interest groups in creating a broad set of policy analyses that our members can use to participate more effectively in local, regional, and national policy venues. In this way, SGIM can support but also extend the reach of individual members. A policy analysis will differ from the product of SGIM individual members by having a defined process of review and input from the SGIM Council and Health Policy Committee. We envision published SGIM policy analyses as a subset of those posted on the SGIM web pages. Published policies would be salient, high quality, peer-reviewed products of general interest to our members. These published analyses would represent collaborative effort among the authors working with the SGIM Council, Health Policy Committee, and the JGIM editorial team. The Wharam article represents a collaboration of this sort. It is an example of the kind of thoughtful policy analysis we hope to support. We would therefore like to highlight some of the article's key features from the point of view of SGIM governance.

First, the analysis was produced by one of SGIM's formally identified committees (Ethics). Analyses by individual SGIM members and others on policy issues can be very valuable, but would not be considered SGIM policy analyses. The path to an SGIM policy analysis (or SGIM issue brief, a shorter document for the website) begins with submission of a synopsis to an appropriate SGIM official committee.

Second, the authors systematically incorporated the views of a broader group of SGIM members beyond the Ethics Committee. Besides reviewing the literature, the authors carried out in-depth interviews with key informants, focus groups with SGIM members at regional meetings, and open forums at SGIM national meetings. The ideas in the paper evolved substantially as the authors interacted with clinicians, educators, and researchers across the country. The final paper speaks with the authority of the many voices it integrates.

Third, the SGIM Council actively participated in producing the document. Initially, the Council supported the initiation of the project by involving regional and national meeting attendees. Later, the Council reviewed and approved the initial draft of the policy analysis paper. Finally, the Council re-reviewed and commented on the final policy analysis draft. The statement thus represents an official SGIM viewpoint and can be used by SGIM Committees and interest groups for reference and dissemination. 
Fourth, the SGIM Health Policy Committee contributed by helping the paper's authors and the Council develop a focused policy statement at the paper's core. Typical medical journal papers present data and appropriately avoid taking positions. Like traditional publications, policy analyses rely on evidence, theory, and literature review as foundations. Policy analyses like this one, however, when carried out in support of a society like SGIM, also represent a defined stance that can be used to take action. Many Health Policy Committee members are highly experienced policy experts. Their expertise enabled the authors of this paper to hone their conclusions into action statements.

Finally, the published paper benefited from the expertise of JGIM editors, reviewers, and editorial staff. The Council had approved the initial draft of the paper submitted to JGIM. The format and quality review criteria for JGIM policy analyses, however, had not yet been established. JGIM worked with the authors to develop an effective format. The final paper contains the same basic information as the initial draft, but it is substantially more readable, shorter, and better supported than the initial draft, thanks to JGIM's editing and review.

The overall process produced a strong work that is a credit to its authors and to the many other SGIM individuals and groups who contributed. It was also a pilot test for the process of developing SGIM policy analyses for JGIM and as such identified potential issues for the future. First, in order to foster the development of future policy analyses from SGIM's committees and interest groups, the policy pathway needs to be more broadly accessible. Methods for integrating health policy and core committee expertise into such analyses beginning from an early stage, for example, are critical.

Second, standard publication formats and quality standards for SGIM policy analyses are needed to support the policy analysis development and review process. Templates could be created to make it easier for authors to prepare policy analyses for publication. Quality guidelines could assist the
Council and reviewers in moving policy analyses forward. In this paper, for example, no formal qualitative analysis of focus group or interview results is documented in the paper, and no surveys or consensus panels were undertaken. SGIM needs to consider what types of methods for assessing membership views on specific subjects are acceptable, and how much exploration of broader views is necessary to assure reasonable consensus.

Finally, because policy analysis is action-oriented, tradeoffs between completeness of preparation and review must be weighed against the effects of delay in the publication timeline. Some issues may be enduring and lend themselves to a more comprehensive approach, while others may be more timelimited and require a method for rapid progression into print.

SGIM expects that the Wharam paper will be used by SGIM committees and members as a starting point for local, regional, and national action. Members who disagree with the paper will still be able to utilize its systematic review of pay for performance issues. Health-care reform activities will inevitably focus attention on how to incentivize quality and will surely demand accountability from providers. We expect that by anticipating potential unintended consequences, and framing them in ethical terms, SGIM members can help shape performance incentives that truly benefit the health of the public.

Corresponding Author: Lisa V. Rubenstein, MD, MSPH, VA Greater Los Angeles at Sepulveda, 16111 Plummer St. (152), North Hills, CA 91343, USA (e-mail: Lisar@rand.org).

\section{REFERENCE}

1. Wharam JF, Paasche-Orlow MK, Farber MJ, et al. High quality care and ethical pay-for-performance: a society of general internal medicine policy analysis. J Gen Intern Med. 2009;24 doi:10.1007/s11606-009-0947-3. 